\title{
Sentinel lymph node biopsy: technique validation at the Setúbal Medical Centre, Portugal
}

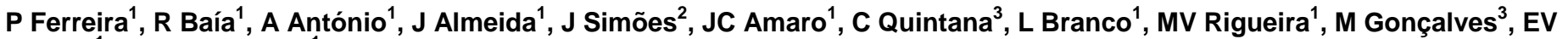 \\ Pereira $^{1}$ and LM Ferreira ${ }^{1}$ \\ ${ }^{1}$ Senology Unit, General Surgery Service, Setúbal Medical Centre, Portugal \\ ${ }^{2}$ Senology Unit, Gynecology \& Obstetrics Service, Setúbal Medical Centre, Portugal \\ ${ }^{3}$ Pathology Service, Setúbal Medical Centre, Portugal
}

\section{Abstract}

Aims: To evaluate the accuracy of sentinel lymph node biopsy in breast cancer patients at this institution, using combined technetium$99 \mathrm{~m}\left({ }^{99 \mathrm{~m}} \mathrm{Tc}\right)$ sulphur colloid and patent blue vital dye.

Methods: From March 2007 to July 2008, 50 patients with a tumour of less than $3 \mathrm{~cm}$ and with clinically negative axillary lymph nodes underwent sentinel lymph node biopsy (SLNB), followed by axillary lymph node dissection (ALND). Sub-areolar ${ }^{99 m}$ Tc sulphur colloid injection was performed the day before surgery, and patent blue vital dye was also injected sub-areolarly at least 5 minutes before surgery. Sentinel lymph node was identified during the surgical procedure, using a gamma probe and direct vision. All sentinel nodes underwent frozen section analysis. Later haematoxylin and eosin staining and immunohistochemical analysis were performed. Finally, SLNB was compared with standard ALND for its ability to accurately reflect the final pathological status of the axillary nodes.

Results: The sentinel lymph node (SLN) was identified in 48 of 50 patients (96\%). The number of sentinel lymph nodes ranged from one to four (mean 1.48) and non-sentinel nodes ranged from seven to 27 (mean 14.33). Of the 48 patients with successfully identified SLNs, $29.17 \%$ (14/48) were histologically positive. Sensivity of the SLN to predict axilla was $93.75 \%$; accuracy was $97.96 \%$. The SLN was falsely negative in one patient-6.25\% (1/16).

Conclusions: The SLNB represents a major advance in the surgical treatment of breast cancer as a minimally invasive procedure predicting the axillary lymph node status. This validation study demonstrates the accuracy of the SLNB and its reasonable false negative rate when performed in our institute. It can now be used as the standard method of staging in patients with early breast cancer at this institution.

Published: 15/01/2009

Received: $11 / 12 / 2008$

ecancer 2009, 3:124 DOI: 10.3332/ecancer.2008.124

Copyright: (c) the authors; licensee ecancermedicalscience. This is an Open Access article distributed under the terms of the Creative Commons Attribution License (http://creativecommons.org/licenses/by/2.0), which permits unrestricted use, distribution, and reproduction in any medium, provided the original work is properly cited.

Competing Interests: The authors have declared that no competing interests exist.

Correspondence to P Ferreira. Email: pedrosf76@hotmail.com 


\section{Introduction}

Breast cancer is the most common malignancy among women in Europe, accounting for $20 \%$ or more of all cancers and representing the leading cause of cancer deaths in females between 35 and 55 years old in Europe. About one in 12 will develop the disease before the age of 75 years, representing a lifetime risk around $8 \%[1,2]$. It is important that effective screening methods and accurate ways for staging and prognosis once the diagnosis has been established are available $[3,4]$. Axillary lymph node dissection (ALND) provides information about disease stage, local control of disease, and helps in the decision making for adjuvant therapy [5-7]. However, for patients with pathologically negative lymph nodes survival rates are not increased by ALND [8], and there are a considerable number of related complications, such as sensory nerve damage, haemorrhaging, seroma formation (20-55\% of cases) $[9,10]$ and chronic lymphoedema of the arm (7-56\%) $[11,12]$.

As about $60-70 \%$ of patients with early breast cancer have no regional axillary lymph node metastasis [12], sentinel lymph node biopsy (SLNB) is an easy to establish, ideal alternative, capable of accurately predicting the state of axillary lymph nodes, avoiding classical axillary lymph node staging and its consequent morbidity.

After being first described by Cabanas et al in 1977 [50], for carcinoma of the penis, the SLNB technique was then used in staging malignant melanoma, as reported in 1992, by Morton et al [13], and more recently for breast carcinoma as reported by Krag et al in 1993 [14] and Giuliano et al in 1994 [15]. The SLNB serves as a stand alone method for determining axillary nodal status, providing physicians with the ability to distinguish positive axillary lymph nodes in a relatively simple, safe, rational and accurate fashion.

The sentinel lymph node (SLN) is the first lymph node to drain the entire lymphatics of the breast. Since metastatic breast cancer cells travel via this route, an SLN free of metastatic cancer predicts the status of the remaining axillary nodes as also negative for metastasis $[16,17]$.

Over the past 14 years, sentinel node biopsy in breast cancer patients has become an exciting research topic. Many studies have shown that SLNB accurately predicts axillary lymph node status [18-20] and is associated with less morbidity than ALND completion $[9,21,22]$. Results from international breast cancer centres show that, with the use of optimal techniques, SLNB predicts axillary nodal status with high accuracy and low clinical false-negative rates [20,23-26]. Many medical centres adopted SLNB without completion of ALND in patients who have a clinical negative SLN, in an effort to decrease the morbidity of axillary lymphoadenectomy while maintaining accurate staging $[27,28]$.

The purpose of this study was to evaluate the accuracy of SLNB at this institution and to thereafter implement it as the standard method of staging in patients with early breast cancer.

Using radiolabelled nanocolloid and patent blue vital dye as tracers, SLNB was performed in patients with breast cancer and its feasibility evaluated for patients in our institution.

\section{Patients}

Fifty consecutive breast cancer patients, with a primary tumour less than $3 \mathrm{~cm}$ and a clinically negative axilla, were included in a prospective study performed between March 2007 and July 2008 at our hospital. Both mastectomy and breast conservation patients were equally eligible. All patients undergoing the study gave their informed consent for sub-areolar injection of radiotracer and patent blue vital dye and for the surgical procedure to be performed. The trial was approved by the institutional review board. The age of the patients ranged from 36 to 79 years, with a mean age of 59.4 years. All patients underwent SLNB and consecutive axillary dissection. Used inclusion and exclusion criteria are listed in Table 1.

\section{Methods}

During study enrolment at our institution, the SLNB technique included the use of technetium-99m ( ${ }^{99 m} \mathrm{Tc}$ ) sulphur colloid and blue dye. The ${ }^{99 m}$ Tc sulphur colloid was prepared by the nuclear medicine departments of two other validated institutions with which our hospital has an agreement (Hospital CUF Descobertas and NuclearMed-Instituto de Medicina Nuclear), and comprised a solution containing $1.0 \mathrm{mCi}(1.0 \mathrm{mCi}$ $=37 \mathrm{MBq}$ ) ${ }^{99 \mathrm{~m}} \mathrm{Tc}$ labelled rhenium sulphide colloid (nanocolloid particles $<80 \mathrm{~nm}-$ Nanocis ${ }^{\circledR}$ ). A total volume of $0.4 \mathrm{ml}$ was injected sub-areolarly 15-24 hours before the operation. Planar scans of the involved breast and axillary area, in anterior and lateral projections, were acquired 15-30 minutes and 3 hours after tracer injection, to ascertain the overall distribution of the 
Table 1: Inclusion and exclusion criteria

\begin{tabular}{|c|c|}
\hline Inclusion Criteria & $\begin{array}{l}\text { - } \text { Age }>18 \text { and }<80 \text { years old } \\
\text { - Clinically and pathologically (FNA, incisional } \\
\text { biopsy, core biopsy/mammotome or excisional } \\
\text { biopsy) diagnosed breast cancer } \\
\text { - } \quad \text { Breast invasive carcinoma in clinical stage } T_{1 / 2} \\
N_{0} M_{0}(\leq 3 \mathrm{~cm})\end{array}$ \\
\hline $\begin{array}{l}\text { Absolute exclusion } \\
\text { criteria }\end{array}$ & $\begin{array}{l}\text { - } \quad \text { Patient's refusal to participate } \\
\text { - } \quad \text { Clinically positive axilla } \\
\text { - } \quad \text { Pregnancy } \\
\text { - } \quad \text { Previous reduction mammoplasty } \\
\text { - } \quad \text { Multicentric tumour diagnosed preoperatively } \\
\text { - } \quad \text { Previous radiotherapy (for another disease) } \\
\text { - History of other neoplasic disease (except } \\
\quad \text { cutaneous tumours non melanoma and in situ } \\
\text { - } \quad \text { Known allergy to radiocolloids or the blue dye }\end{array}$ \\
\hline $\begin{array}{l}\text { Relative exclusion } \\
\text { criteria }\end{array}$ & $\begin{array}{l}\text { - Previous surgery to the axilla } \\
\text { - Multifocal Carcinoma }\end{array}$ \\
\hline
\end{tabular}

FNA: fine-needle aspiration.

radiotracer and identify SLN. A skin mark was made over the first spot to become hot to facilitate SLN location during the operation.

With the patient already anaesthesiated, and at least five minutes before surgery, blue dye (Bleu Patente V Sodique Guerbet $^{\circledR} 2.5 \%$ ) was injected sub-areolarly in four deposits around the nipple totalling $2 \mathrm{ml}$. The patient was then prepped and draped in the usual sterile fashion. A low-transverse axillary incision was made, and a handheld gamma probe (Neo2000 ${ }^{\circledR}$ Gamma Detection System, Neoprobe Corp., OH, USA) was used to guide the dissection for hot-spot detection. A hot spot was defined as the spot that had the greatest radioactivity counts in the lymphatic basin, which was at least 25 counts per ten seconds or greater. All 'hot' nodes and blue nodes were removed. After removing all nodes, the activity of the resection bed was assessed and should be less than $10 \%$ of the hottest, most radioactive excised lymph node. The SLN specimen was sent for frozen section analysis, and regardless of the result, all patients underwent ALND.

\section{Pathological examination}

All blue and 'hot' SLN specimens were carefully identified and evaluated by a pathologist. All lymph nodes in the specimen were identified and dissected from the surrounding tissue by the pathologist. The number of nodes and their dimensions were accessed. SLNs smaller than $10 \mathrm{~mm}$ did not undergo frozen section analysis, SLNs $\leq 5 \mathrm{~mm}$ were processed and totally included in paraffin blocks (one block with all SLNs $\leq 5 \mathrm{~mm}$ ), SLNs $>5 \mathrm{~mm}$ and $<10 \mathrm{~mm}$ were sectioned $\pm 2 / 3 \mathrm{~mm}$ perpendicularly to the longitudinal axis, processed and totally included in paraffin (one block per SLN $>5$ and $<10 \mathrm{~mm}$ ) and SLNs $\geq 10 \mathrm{~mm}$ underwent frozen section analysis. SLNs $>10$ $\mathrm{mm}$ were longitudinally bisected and one of the half sections was submitted to frozen section analysis (one to three frozen sections per analysis) and/or cytological analysis (imprint). Those not subjected to frozen sectioning were then processed and totally included in paraffin (two blocks per SLN $\geq 10 \mathrm{~mm}$ ). All SLNs were sectioned (100 $\mu \mathrm{m}$ sections) and every other section (first, third, fifth, seventh, etc.) stained with haematoxylin and eosin (H\&E). The corresponding section (second, fourth, sixth, eight, etc.) was stained immunohistochemically, using a cytokeratin cocktail of monoclonal antibodies that recognize a wide range of high- and low-molecular weight keratin peptides $\left(A E 1 / A E 3\right.$, Dako $\left.^{\circledR}\right)$. Both SLNs and non-nodal tissue collected from ALND were sectioned and examined for the presence of tumour cells.

\section{Statistical analysis}

Important data, including patient demographics and tumour characteristics, were recorded in a Microsoft ${ }^{\circledR}$ Office Excel spreadsheet. 
Table 2: Patient clinical characteristics $(n=50)$

\begin{tabular}{|l|l|}
\hline Variable & $\mathbf{N}^{\circ}(\%)$ \\
\hline Age (years) & \\
\hline range & $36-79$ \\
\hline mean age & 59,4 \\
\hline Menopausal status & \\
\hline Premenopausal & $13(26 \%)$ \\
\hline Postmenopausal & $35(70 \%)$ \\
\hline Male patients & $2(4 \%)$ \\
\hline Breast quadrant & \\
\hline Lateral superior & $25(50 \%)$ \\
\hline Lateral inferior & $2(4 \%)$ \\
\hline Medial superior & $14(28 \%)$ \\
\hline Medial inferior & $3(6 \%)$ \\
\hline Central & $2(4 \%)$ \\
\hline Superior quadrants transition & $2(4 \%)$ \\
\hline Lower quadrants transition & $2(4 \%)$ \\
\hline Surgery performed & \\
\hline Mastectomy & $17(34 \%)$ \\
\hline Breast conservative surgery & $33(66 \%)$ \\
\hline
\end{tabular}

Table 3: Disease characteristics $(n=50)$

\begin{tabular}{|l|l|}
\hline Variable & $\mathbf{N}^{\mathbf{0}} \mathbf{( \% )}$ \\
\hline Biopsy type & \\
\hline Core & $15(30 \%)$ \\
\hline Excisional & $2(4 \%)$ \\
\hline FNA & $33(66 \%)$ \\
\hline Tumour size (cm) & \\
\hline T1b & $7(14 \%)$ \\
\hline T1c & $29(58 \%)$ \\
\hline T2 & $14(28 \%)$ \\
\hline Tumour histology & \\
\hline Infiltrating ductal & $42(84 \%)$ \\
\hline Infiltrating lobular & $2(4 \%)$ \\
\hline Mixed ductal/lobular & $1(2 \%)$ \\
\hline Papillary invasive & $2(4 \%)$ \\
\hline Micropapillary invasive & $1(2 \%)$ \\
\hline Mucinous & $2(4 \%)$ \\
\hline Grade & \\
\hline 1 & $8(16 \%)$ \\
\hline 2 & $35(70 \%)$ \\
\hline 3 & $7(14 \%)$ \\
\hline Receptor status & \\
\hline ER+/PR+ & $40(80 \%)$ \\
\hline ER+/PR- & $3(6 \%)$ \\
\hline ER-/PR+ & $5(10 \%)$ \\
\hline ER-/PR- & $2(4 \%)$ \\
\hline Her2/neu & \\
\hline Positive & $7(14 \%)$ \\
\hline Negative & $43(86 \%)$ \\
\hline FNA, Fine-needle aspiration; ER, oestrogen receptor; \\
\hline $\begin{array}{l}\text { PR, progesterone receptor; Her2/neu, human epidermal } \\
\text { growth factor receptor 2. }\end{array}$ \\
\hline
\end{tabular}

Accuracy was defined as the percentage of patients in which the sentinel node status has accurately represented the lymph node status of patient. False negative (FN) rate was defined as the percentage of patients who had histologically negative SLNs but other positive axillary nodes. Fisher's exact test and $x^{2}$ tests were used to analyse the impact of different factors on this method.

\section{Results}

A total of 50 consenting patients were enrolled in the study. The clinical data of the patients and their disease characteristics are shown in Tables 2 and $\underline{3}$. All the 50 patients who underwent lymphoscintigraphy had lymphatic drainage towards the axilla. 
Table 4: Summary of sentinel node biopsy

\begin{tabular}{|l|l|}
\hline Parameters & $\mathbf{N}^{0} \mathbf{( \% )}$ \\
\hline Patients with surgically identified SLN & $48 / 50(96 \%)$ \\
\hline Patients with lymph node metastasis & $15 / 50(30 \%)$ \\
\hline Patients without lymph node metastasis & $35 / 50(70 \%)$ \\
\hline Patients with positive SLN & $14 / 48(29,17 \%)$ \\
\hline Patients with false negative SLN & $1 / 48(2,08 \%)$ \\
\hline Patients with SLN and ALN concordance & $47 / 48(97,92 \%)$ \\
\hline Patients with only SLN metastasis & $5 / 48(10,42 \%)$ \\
\hline
\end{tabular}

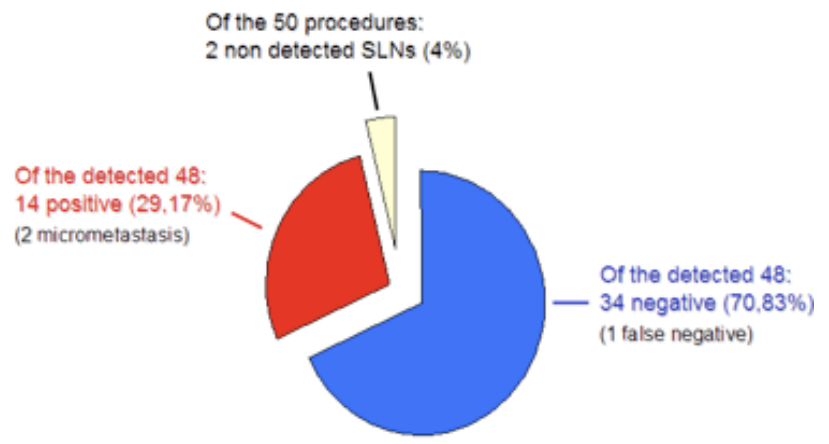

Figure 1: Summary of results.

Breast surgery consisted of mastectomy in 17 patients $(34 \%)$ and breast conservative surgery in 33 patients $(66 \%)$. The average primary tumour size in the study population was 1.9 $\mathrm{cm}$, ranging from 0.6 to $4.0 \mathrm{~cm}$, including $36 \mathrm{~T} 1$ tumours $(72 \%)$ and 14 T2 tumours (28\%). There was only one tumour of more than $3 \mathrm{~cm}$ after pathological examination. As for histological features, there were 42 infiltrating ductal cancers (84\%), two infiltrating lobular cancers (4\%), one mixed carcinoma (2\%), two papillary invasive carcinomas (4\%), one micropapillary invasive carcinoma (2\%) and two mucinous carcinomas (4\%).

The SLN was successfully detected in 48 of the 50 patients, corresponding to a surgical overall identification rate of $96 \%$ using both dye and radioisotope, not statistically different to other equivalent studies. The patients in which detection was not accomplished were 57 and 76 years old, with a tumour size of 15 and $16 \mathrm{~mm}$, respectively, both in the lateral superior quadrant location.

In the 48 successful cases, the number of nodes detected ranged from one to four, and the mean number of sentinel lymph nodes per case was 1.48. All SLNs were located at level 1 of the axilla. The number of dissected non-sentinel lymph nodes ranged from seven to 25 , with a total of 688 nodes and a mean of 14.33 nodes/case.

A total of 14 patients (29.17\%) had SLN positive for metastasis by definitive histological analysis, two of which were micrometastasis $(<2 \mathrm{~mm}$ ), not detected by frozen section analysis. Only $25 \%$ of cases with T1 lesions were found to have axillary lymph node metastasis compared to $42.86 \%$ of cases with T2 lesions. SLN analysis was negative in 34 patients $(70.83 \%)$; however, metastatic cells were found in two lymph nodes of one patient after axillary dissection, accounting for the only FN result (FN rate 6.25\% (1/16)), (Figure 1 and Table 4).

The FN finding occurred in a 79-year-old woman with a $28-\mathrm{mm}$ ductal invasive carcinoma located in the medial superior quadrant of the breast.

These data give us a sensivity of $93.75 \%$, a specificity of $100 \%$, a positive predictive value of $100 \%$ and a negative predictive value of $97.06 \%$, with an overall accuracy of $97.96 \%$ for predicting the malignant status of the axilla.

In five cases, the SLN was the only positive node, four of which had a ductal invasive tumour histological type and one had a micropapillary invasive pattern. 
Table 5: Identification and false-negative rates from similar sentinel lymph node biopsy studies

\begin{tabular}{|c|c|c|c|c|}
\hline Author & Year & $\begin{array}{c}\mathrm{N}^{0} \text { of } \\
\text { patients }\end{array}$ & $\begin{array}{l}\text { ID } \\
\text { rate }\end{array}$ & $\begin{array}{l}\mathrm{FN} \\
\text { rate }\end{array}$ \\
\hline O'Hea et al. ${ }^{39}$ & 1998 & 60 & $93 \%$ & $15 \%$ \\
\hline Barnwell et $a l^{40}$ & 1998 & 42 & $90 \%$ & $0 \%$ \\
\hline Nwariaku et al. ${ }^{18}$ & 1998 & 190 & $81 \%$ & $4 \%$ \\
\hline $\operatorname{Kern}^{41}$ & 1999 & 40 & $97.5 \%$ & $0 \%$ \\
\hline Mertz et al. ${ }^{42}$ & 1999 & $\begin{array}{l}47 \\
32\end{array}$ & $\begin{array}{l}97.9 \% \\
96.9 \%\end{array}$ & $\begin{array}{c}0 \% \\
10 \%\end{array}$ \\
\hline Borestein et al. ${ }^{43}$ & 2000 & 130 & $96.9 \%$ & $0 \%$ \\
\hline Smith et al. ${ }^{44}$ & 2000 & $\begin{array}{l}19 \\
19\end{array}$ & $\begin{array}{l}100 \% \\
94.7 \%\end{array}$ & $\begin{array}{c}0 \% \\
20 \%\end{array}$ \\
\hline McMasters et al. ${ }^{36}$ & 2001 & 85 & $98.8 \%$ & $5.9 \%$ \\
\hline Donahue $^{45}$ & 2001 & 42 & $100 \%$ & $8.3 \%$ \\
\hline $\mathrm{Kern}^{46}$ & 2002 & 187 & $98.4 \%$ & $0 \%$ \\
\hline Chagpar et al. ${ }^{47}$ & 2004 & $\begin{array}{c}1431 \\
148 \\
183\end{array}$ & $\begin{array}{l}91.1 \% \\
99.3 \% \\
95.6 \%\end{array}$ & $\begin{array}{l}8.6 \% \\
8.3 \% \\
8.9 \%\end{array}$ \\
\hline D'Eredita $e t$ al. ${ }^{37}$ & 2005 & $\begin{array}{c}115 \\
40 \\
40\end{array}$ & $\begin{array}{l}94.8 \% \\
97.5 \% \\
100 \%\end{array}$ & $\begin{array}{l}9 \% \\
0 \% \\
0 \%\end{array}$ \\
\hline This study & 2008 & 50 & $96 \%$ & $6.25 \%$ \\
\hline
\end{tabular}

ID: identification; FN: false negative

Our detection rate reached $100 \%$ after six SLNB procedures, and our FN occurred at the 15th procedure.

\section{Discussion}

The SLN is the first lymph node to receive the lymphatic drainage of a metastatic tumour. In theory, there is a spread of tumour cells from sentinel nodes to other nodes. If so, further spread of cancer cells can be predicted by the SLNs $[13,14]$. The SLNB procedure in breast cancer patients is already a regular procedure in western countries.

The purpose of this study was to prospectively evaluate the accuracy of the SLNB in patients with early stage breast cancer undergoing this procedure by surgeons at this institution, with completion of ALND for confirmation.

Current literature frequently mentions that an identification rate greater than $90 \%$ and a $\mathrm{FN}$ rate of no more than $5-10 \%$ is a reasonable goal for surgeons and institutions developing the SLNB technique [29]. The accuracy of SLNs to predict axillary status should ideally be greater than $95 \%$.

The identification rate in this study, using sub-areolar injections of dye/tracer, is $96 \%$. The first study of Giuliano et al reported a $65 \%$ identification rate with blue dye [15], and their more recent studies achieve an identification rate of $93 \%$ and $99 \%$ of cases [30,31].
Our detection failures occurred in the first and sixth cases, gradually improving thereafter the dissection and identification of the SLN specimen. An identification rate of $100 \%$ in the later cases of our study reflects the plateau of the learning curve for this technique [32]. Some studies have indicated that the success rate is lower in patients older than 50 years [33], which is in accordance with our results.

Some reports suggest that the radiotracer and the blue dye are complementary, facilitating SLN detection when used together, thus accelerating the learning curve [34-36].

Despite controversy, we adopted the sub-areolar site for blue dye and radiotracer injection based on the hypothesis that breast drains lymph as a single unit, due to its embryological development from ectodermal primitive milk streak that becomes the areolar complex, there is also some evidence of high SLN identification rate and low $\mathrm{FN}$ rates and a rapid learning curve using this site of injection [37].

The FN rate is of great importance, especially as the true axillary nodal status has prognostic value and that this procedure is to be applied as a treatment protocol. In our study, the observed $\mathrm{FN}$ rate was $6.25 \%$, not statistically different to other equivalent studies. Several series showed that FN SLNs occurred in tumours larger than $15 \mathrm{~mm}[34,38]$. In this study, the false-negative SLN occurred in a 28-mm tumour.

In our study, the identification rate and $\mathrm{FN}$ rate are similar to other preliminary studies that used radiotracer and blue dye (Table 5). 
Table 6: Comparison of this study with Cody's meta-analysis and ALMANAC's multi-centre study

\begin{tabular}{|l|c|c|c|c|c|c|}
\hline \multicolumn{1}{|c|}{ Author } & Year & $\begin{array}{c}\mathbf{N}^{\circ} \text { of } \\
\text { patients }\end{array}$ & ID rate & FN rate & Sensitivity & Accuracy \\
\hline Cody's $^{29}$ meta-analysis & 2001 & 1155 & $\begin{array}{c}92.73 \% \\
(1071 / 1155)\end{array}$ & $\begin{array}{c}5.04 \% \\
(21 / 417)\end{array}$ & $\begin{array}{c}94.96 \% \\
(396 / 417)\end{array}$ & $\begin{array}{c}98.02 \% \\
(1042 / 1063)\end{array}$ \\
\hline $\begin{array}{l}\text { ALMACAC's } \\
\text { multicentre study }\end{array}$ & 2006 & 836 & $\begin{array}{c}96.05 \% \\
(803 / 836)\end{array}$ & $\begin{array}{c}6.74 \% \\
(19 / 282)\end{array}$ & $\begin{array}{c}93.26 \% \\
(263 / 282)\end{array}$ & $\begin{array}{c}97.38 \% \\
(782 / 803)\end{array}$ \\
\hline This study & 2008 & 50 & $96 \%(48 / 50)$ & $\begin{array}{c}6.25 \% \\
(1 / 16)\end{array}$ & $\begin{array}{c}93.75 \% \\
(15 / 16)\end{array}$ & $\begin{array}{c}97.96 \% \\
(48 / 49)\end{array}$ \\
\hline
\end{tabular}

ID: identification; $\mathrm{FN}$ : false negative

Barnwell et al [40] assessed the success and accuracy of SLNB with blue dye and ${ }^{99 \mathrm{~m}}$ Tc sulphur colloid compared to ALND. SLN was found in 38 of the $42(90 \%)$ cases with no FNs. In a study by Nwriaku et al [18], using both blue dye and radiotracer, 119 women with breast carcinoma who underwent SLN and ALND, the SLN identification rate was $81 \%$ with one $\mathrm{FN}$ in a patient with axillary disease (FN rate of $4 \%$ ). Mertz et al [42] analysed the relevance of the sub-areolar injection for SLN detection in multiple foci breast cancer, comparing 79 breast cancer patients who underwent ${ }^{99 \mathrm{~m}} \mathrm{Tc}$ filtered sulphur colloid sub-areolar injection (group I) with 32 patients who underwent peritumoural injection (group II). SLN was detected in $97.9 \%$ and $96.9 \%$ of the cases, respectively. No FNs were observed in group I and one $\mathrm{FN}$ in group II (FN rate 10\%), which was related to a cancer with histological multiple invasive foci. Borgstein et al [43] performed periareolar injection of blue dye and peritumoural radioisotope in 130 patients and achieved a $96.9 \%$ identification rate and a $0 \% \mathrm{FN}$ rate. Smith et al [44] compared 19 patients who received ${ }^{99 m}$ Tc sub-areolar and peritumoural blue dye injections with 19 patients who received peritumoural injection of both blue dye and radiotracer. SLNs were found in all patients of the first group and in 18 patients of the second group. The $\mathrm{FN}$ rate was $0 \%$ for the first group and $20 \%$ for the second group. McMasters et al [36] documented a $98.8 \%$ identification rate and a $5.9 \% \mathrm{FN}$ rate, using sub-areolar radiotracer injection and peritumoural blue dye injection in 85 patients. Donahue [45] obtained an identification rate of $100 \%$ and a $\mathrm{FN}$ rate of $8.3 \%$, using peritumoural radioisotope and sub-areolar blue dye injection in 42 patients. Kern [46] reported an identification rate of $98.4 \%$, a FN rate of $0 \%$ and an accuracy of $100 \%$ for predicting the malignant status of the axilla in a study with 187 patients, using sub-areolar injection dual-tracer technique. Chapgar et al [47], reported a multi-centre clinical trial on 3961 patients. For 1762 patients given radiotracer injection, identification rates of $91.1 \%$ for peritumoural injections, $99.3 \%$ for sub-areolar injections and $95.6 \%$ for periareolar injections were obtained, with $\mathrm{FN}$ rates between $8 \%$ and 9\%. D'Eredita et al [37] achieved high SLN identification rates $(94.2-100 \%)$ but with $\mathrm{FN}$ rates of $9 \%$ in their first study, but this dropped to $0 \%$ in later studies, showing clearly the importance an adequate learning period, also sustained by Cody et al [48].

Our results are also similar to reports based on larger sample series such as Cody's [29] meta-analysis of 12 validation studies from 1993 to 1999 and ALMANAC Trialists Group's [49] prospective multi-centre validation study performed to quantify identification and FN rates of SLNB and evaluate factors influencing them, both using radiotracer and blue dye (Table 6 ) $[29,49]$.

All these studies demonstrate that SLNB can accurately predict the axillary lymph node status. The FN results suggest that a correct inspection of the axilla and removal of any nodes that appear abnormal is an important part of the SLN procedure.

\section{Conclusion}

Sentinel lymph node biopsy is considered to be the goldstandard method in staging patients with early-stage breast cancer and a clinically negative axilla, providing important prognostic information to plan adjuvant treatment and avoiding the morbidity of invasive ALND.

The present study reflects our experience, indicating that the SLNB can be performed in an accurate, safe and reproducible manner in our hospital and is now ready to be adopted as the standard staging procedure for patients with early breast cancer.

\section{Acknowledgements}

Special thanks to the histopathology and special examinations units. 


\section{References}

1. Jemal A, Clegg LX, Ward E, Ries LA, Wu X, Jamison PM, Wingo PA, Howe HL, Anderson RN and Edwards BK (2004) Annual report to the nation on the status of cancer, 1975-2001, with a special feature regarding survival Cancer 101 3-27 PMID: 15221985 doi: 10.1002/ cncr.20288

2. Coleman MP, Estève J, Damiecki $P$, Arslan A and Renard H (1993) Trends in Cancer Incidence and Mortality IARC Scientific Publications No. 121 (Lyon: International Agency for Research on Cancer)

3. Rubio IT, Korourian S, Cowan C, Krag DN, Colvert M and Klimberg VS (1998) Sentinel lymph node biopsy for staging breast cancer Am J Surg 176 532-7 PMID: $\underline{9926785}$ doi: $10.1016 /$ S0002-9610(98)00264-5

4. Strickland AH, Beechey-Newman N, Steer CB and Harper PG (1998) Sentinel node biopsy: an in depth appraisal Crit Rev Oncol Hematol 44 45-70 PMID 12398999 doi: 10.1016/S1040-8428(02)00018-5

5. Louis-Sylvestre C, Clough K, Asselain B, Vilcoq Jr, Salmon RJ, Campana F and Fourquet A (2004) Axillary treatment in conservative management of operable breast cancer: dissection or radiotherapy? Results of a randomized study with 15 years of follow-up $\mathbf{J}$ Clin Oncol 22 97-101 PMID: 14701770 doi: 10.1200/JCO. $\underline{2004.12 .108}$

6. Motomura $\mathrm{K}$, Komoike $\mathrm{Y}$, Nagumo $\mathrm{S}$, Kasugai $\mathrm{T}$, Hasegawa Y, Inaji H, Noguchi S and Koyama H (2002) Sentinel node biopsy to avoid axillary lymph node dissection in breast cancer Breast Cancer 9 337-43 PMID: 12459716 doi: 10.1007/BF02967614

7. Roumen RM, Kuijt GP, Liem IH and van Beek MW (2001) Treatment of 100 patients with sentinel node-negative breast cancer without further axillary dissection $\mathbf{B r} \mathbf{J}$ Surg 88 1639-43 PMID: 11736979 doi: 10.1046/j.00071323.2001.01935.x

8. Fisher B, Redmond C, Fisher ER et al (1985) Ten year results of a randomized clinical trial comparing radical mastectomy and total mastectomy with and without radiation N Engl J Med 312 674-81 PMID: 3883168

9. Blanchard DK, Donohue JH, Reynolds C and Grant CS (2003) Relapse and morbidity in patients undergoing sentinel lymph node biopsy alone or with axillary dissection for breast cancer Arch Surg 138 482-7 PMID: 12742949 doi: 10.1001/archsurg.138.5.482

10. Ivens $\mathrm{D}$, Hoe $\mathrm{AL}$, Podd $\mathrm{TJ}$, Hamilton $\mathrm{CR}$, Taylor I and Royle GT (1992) Assessment of morbidity from complete axillary dissection $\mathrm{Br} \boldsymbol{J}$ Cancer 66 136-8 PMID: 1637663
11. Hack TF, Cohen L, Katz J, Robson LS and Goss P (1999) Physical and psychological morbidity after axillary lymph node dissection for breast cancer J Clin Oncol 17 143-9 PMID: 10458227

12. Gerber L, Lampert M, Wood C, Duncan M, D'Angelo T, Schain W et al (1992) Comparison of pain, motion, and edema after modified radical mastectomy vs local excision with axillary dissection and radiation Breast Cancer Res Treat 21 139-45 PMID: 1627817 doi: 10.1007/BF01836960

13. Morton DL, Wen DR, Wong JH et al (1992) Technical details of intraoperative mapping for early stage melanoma Arch Surg 127 392-9 PMID: 1558490

14. Krag DN, Weaver DL and Alex JC (1992) Fairbank JT Surgical resection and radio localization of the sentinel lymph node in breast cancer using a gamma probe Surg Oncol 2 335-9 doi: 10.1016/0960-7404(93)90064-6

15. Giuliano AE, Kiegan DM, Guenther JM et al (1994) Lymphatic mapping and sentinel lymphadenectomy for breast cancer Ann Surg 220 391-401 PMID: 8092905

16. Reynolds C, Mick R, Donohue JH, Grant CS, Farley DR, Callans LS et al (1999) Sentinel lymph node biopsy with metastasis: can axillary dissection be avoided in some patients with breast cancer? J Clin Oncol 17 1720-6 PMID: 10561208

17. Krag DN, Weaver DL, Askikaga T et al (1998) The sentinel node in breast cancer multicentre validation study $\mathbf{N}$ Engl J Med 339 941-6 PMID: 9753708 doi: 10.1056/ NEJM199810013391401

18. Nwariaku FE, Euhus DM, Beitsch PD, Clifford E, Erdman W, Mathews D, Albores-Saavedra J, Leitch MA and Peters GN (1998) Sentinel lymph node biopsy, an alternative to elective axillary dissection for breast cancer $\mathbf{A m ~ J}$ Surg 176 529-31 PMID: 9926784 doi: 10.1016/S00029610(98)00276-1

19. Hansen NM, Grube BJ and Giuliano AE (2002) The time has come to change the algorithm for the surgical management of early breast cancer Arch Surg 137 1131-5 PMID: 12361418 doi: 10.1001/archsurg.137.10. 1131

20. Chung MA, Steinhoff MM and Cady B (2002) Clinical axillary recurrence in breast cancer patients after a negative sentinel node biopsy Am J Surg 184 310-4 PMID: 12383890 doi: 10.1016/S0002-9610(02)00956-X

21. Schijven MP, Vingerhoets AJ, Rutten HJ, Nieuwenhuijzen GA, Roumen RM, van Bussel ME and Voogd AC (2003) Comparison of morbidity between axillary lymph node dissection and sentinel node biopsy Eur J Surg Oncol 29 341-50 PMID: 12711287 doi: 10.1053/ejso.2002.1385 
22. Veronesi U, Paganelli G, Viale G, Luini A, Zurrida S, Galimberti V et al (2003) A randomized comparison of sentinel-node biopsy with routine axillary dissection in breast cancer N Engl J Med 349 546-53 PMID: 12904519 doi: 10.1056/NEJMoa012782

23. Smillie T, Hayashi A, Rusnak C, Dunlop W, Donald J and Van Der Westhuizen N (2001) Evaluation of feasibility and accuracy of sentinel node biopsy in early breast cancer Am J Surg 181 427-30 PMID: 11448435 doi: 10.1016/S0002-9610(01)00613-4

24. Reitsamer R, Peintinger F, Prokop E, Rettenbacher L and Menzel C (2004) 200 Sentinel lymph node biopsies without axillary lymph node dissection-no axillary recurrences after a 3-year follow-up $\mathrm{Br} \mathbf{J}$ Cancer 90 1551-4 PMID: 15083184 doi: 10.1038/sj.bjc.6601765

25. Guenther JM, Hansen NM, DiFronzo LA, Giuliano AE, Collins JC, Grube BL and O'Connell TX (2003) Axillary dissection is not required for all patients with breast cancer and positive sentinel nodes Arch Surg 138 52-6 PMID: 12511150 doi: 10.1001/archsurg.138.1.52

26. Guenther JM, Hansen NM, DiFronzo LA, Giuliano AE, Collins JC, Grube BL and O'Connell TX (2003) Axillary dissection is not required for all patients with breast cancer and positive sentinel nodes Arch Surg 1381159 (comment)

27. Nano MT, Kollias J, Farshid G, Gill PG and Bochner M (2002) Clinical impact of false-negative sentinel node biopsy in primary breast cancer $\mathbf{B r}$ J Surg 89 1430-4 PMID: 12390387 doi: 10.1046/j.1365-2168.2002.02233.x

28. Noguchi M (2003) Is it necessary to perform prospective randomized studies before sentinel node biopsy can replace routine axillary dissection? Breast Cancer 10 179-87 PMID: 12955029 doi: 10.1007/BF02966716

29. Del Bianco P, Zavagno G, Burelli P et al; GIVOM (2008) Morbidity comparison of sentinel lymph node biopsy vs conventional axillary lymph node dissection for breast cancer patients: results of the sentinella-GIVOM Italian randomised clinical trial Eur J Surg Oncol 345 508-13 PMID: 17614245

30. Cody HS (2001) Clinical aspects of sentinel node biopsy Breast Cancer Res 32 104-8 PMID: 11250755 doi: $10.1186 /$ bcr280

31. Giuliano AE, Jones RC, Brennan M et al (1997) Sentinel lymphadenectomy in breast cancer J Clin Oncol 15 2345-50 PMID: 9196149

32. Giuliano AE, Haigh PI, Brennan MB et al (2000) Prospective observational study of sentinel lymphadenectomy without further axillary dissection in patients with sentinel node negative breast cancer $J$ Clin Oncol 18 2553-9 PMID: 10893286
33. Cox CE, Salud CJ, Cantor A et al (2001) Learning curves for breast cancer sentinel lymph node mapping on surgical volume analysis J Am Coll Surg 193 593-600 PMID: 11768674 doi: 10.1016/S1072-7515(01)01086-9

34. McMasters KM, Tuttle TM, Carlson DJ et al (2000) Sentinel lymph node biopsy for breast cancer: a suitable alternative to routine axillary dissection in multi-institutional practice when optimal technique is used J Clin Oncol 18 2560-6 PMID: 10893287

35. Albertini JJ, Lyman GH, Cox C et al (1996) Lymphatic mapping and sentinel node biopsy in the patient with breast cancer JAMA 276 1818-22 PMID: 8946902 doi: 10.1001/jama.276.22.1818

36. O'Hea JJ, Hill ADK, El-Shirbiny AM et al (1998) Sentinel lymph node biopsy in breast cancer: initial experience at Memorial Slogan Kettering Cancer Center J Am Coll Surg 186 423-7 PMID: 9544956 doi: 10.1016/S10727515(98)00060-X

37. McMasters KM, Wong SL, Martin RC et al (2001) Dermal injection of radioactive colloid is superior to peritumoral injection for breast cancer sentinel lymph node biopsy: results of a multi-institutional study Ann Surg 233 676-87 PMID: 11360892 doi: 10.1097/ 00000658-200105000-00012

38. D'Eredita G, Giardina C, Guerrieri AM and Berardi T (2006) A further validation of subareolar injection technique for breast sentinel lymph node biopsy Ann Surg Oncol 135 701-7 PMID: 16523366 doi: 10.1245/ASO.2006.04. $\underline{027}$

39. Veronesi U, Paganelli G, Galimberti JM et al (1997) Sentinel node biopsy to avoid axillary dissecation in breast cancer with clinically negative lymph nodes Lancet 349 1864-7 PMID 9217757 doi: 10.1016/S01406736(97)01004-0

40. O'Hea BJ, Hill ADK, El-Shirbiny AM et al (1998) Sentinel lymph node biopsy in breast cancer: initial experience at Memorial Sloan-Kettering Cancer Center J Am Coll Surg 186 423-7 PMID: 9544956 doi: 10.1016/S10727515(98)00060-X

41. Barnwell JM, Arredondo MA, Kollmorgen D, Gibbs JF, Lamonica D, Carson W, Zhang P, Winston J and Edge SB (1998) Sentinel node biopsy in breast cancer Ann Surg Oncol 52 126-30 PMID: 9527265

42. Kern K (1999) Sentinel lymph node mapping in breast cancer using subareolar injection of blue dye $\mathbf{J ~ A m ~ C o l l ~}$ Surg 189 539-45 PMID: 10589589 doi: 10.1016/S10727515(99)00200-8

43. Mertz L, Mathelin C, Marin C, Gairard B, Chenard MP, Brettes JP, Bellocq JP and Constantinesco A (1999) Subareolar injection of $99 \mathrm{~m}-\mathrm{Tc}$ sulfur colloid for 
sentinel node identification in multifocal invasive breast cancer Bull Cancer 86 939-45 PMID: 10586110

44. Borgstein PJ, Meijer S, Pijpers RJ and van Diest PJ (2000) Functional lymphatic anatomy for sentinel lymph node in breast cancer Ann Surg 232 81-9 PMID: 10862199 doi: 10.1097/00000658-200007000-00012

45. Smith LF, Cross MJ and Klimberg VS (2000) Subareolar injection is a better technique for sentinel lymph node biopsy Am J Surg 180 434-7 PMID: 11182393 doi: 10.1016/S0002-9610(00)00521-3

46. Donahue EJ (2001) Sentinel node imaging and biopsy in breast cancer patients $\boldsymbol{A m} \boldsymbol{J}$ Surg 182 426-8 PMID: 11720685 doi: 10.1016/S0002-9610(01)00731-0

47. Kern KA (2002) Concordance and validation study of sentinel lymph node biopsy for breast cancer using subareolar injection of blue dye and technetium $99 \mathrm{~m}$ sulphur colloid J Am Coll Surg 195 467-75 PMID: 12375751 doi: $10.1016 / S 1072-7515(02) 01312-1$

48. Chagpar A, Martin RC III, Chao C et al (2004) Validation of subareolar and peritumoral injection techniques for breast sentinel lymph node biopsy Arch Surg 139 61420 PMID 15197087

49. Cody HS, Hill ADK, Tran KN et al (1999) Credentialing for breast lymphatic mapping: how many cases are enough? Ann Surg 229 723-8 PMID 10235531

50. Goyal A, Newcombe RG, Chhabra A and Mansel RE; ALMANAC Trialists Group United Kingdom (2006) Factors affecting failed localisation and false-negative rates of sentinel node biopsy in breast cancer: results of the ALMANAC validation phase Breast Cancer Res Treat 992 203-8 PMID: 16541308 doi: 10.1007/s10549-0069192-1

51. Cabanas RM (1977) An approach for the treatment of penile carcinoma Cancer 39 456-66 PMID 837331 